\title{
Over the counter sale of abortion pills - time to act now
}

\section{Ritu Sharma*, Mamta Gupta, Shakti Sharma}

NDMC Medical College \& Hindu Rao Hospital, Delhi, India

Received: 22 May 2015

Accepted: 06 June 2015

\section{*Correspondence:}

Dr. Ritu Sharma,

E-mail: drritu661@gmail.com

Copyright: (C) the author(s), publisher and licensee Medip Academy. This is an open-access article distributed under the terms of the Creative Commons Attribution Non-Commercial License, which permits unrestricted non-commercial use, distribution, and reproduction in any medium, provided the original work is properly cited.

\begin{abstract}
Background: Government of India has approved abortion pill for termination of early pregnancy. But over the counter availability of this drug instead has earned a bad name for this miracle drug. The aim of this study was to find out the incidence of over the counter availability of abortion pills, the outcome associated with this practice and what cost society has ultimately to pay for this unethical practice.

Methods: This is a retrospective observational study. Among 200 patients who reported to Gynecology emergency with signs and symptoms suggestive of abortion process, those with history of abortion pill intake without prescription were included in the study group and their records were evaluated.

Results: 70 patients who bought abortion pills over the counter were included in the study group. 90\% (63/70) patients were not using any kind of contraceptive method. Only 55.71\% (39/70) patients took the abortion pills as per the recommended standard protocol. Gestational age was $\leq 8$ weeks in $45.71 \%$ (32/70) patients only. Most common presenting complaint was varying amount of bleeding per vaginum followed by abdominal pain met in $97.14 \%$ (68/70) and 30\% (21/70) patients respectively. 7.14\% (5/70) patients presented to emergency in shock. Final diagnosis was complete abortion in $21.42 \%$ (15/70) patients, incomplete abortion in $47.14 \%$ (33/70), missed abortion in $11.42 \%$ ( $8 / 70$ ), septic abortion in $7.14 \%$ ( 5/70), threatened abortion in 5.71\% (4/70), ectopic pregnancy in $5.71 \%$ (4/70) and molar pregnancy in $1.42 \%$ (1/70) patients and they were managed accordingly as per standard guidelines. Conclusion: The women in India should be aware of their legal right to safe abortion. They should stop buying the drug without prescription as medical abortion facilities are being made easily available, accessible and affordable to all. However strict ban on over the counter availability of abortion pills can make the situation worse.
\end{abstract}

Keywords: Medical abortion, Abortion pill, Mifepristone, Misoprostol, Unsafe abortions

\section{INTRODUCTION}

According to WHO throughout the world hemorrhage, sepsis and unsafe abortions are the leading causes of maternal mortality; ${ }^{1,2}$ the latter being responsible for $13 \%$ of maternal deaths., ${ }^{3,4}$ Unsafe abortions include selfinduced abortions and those performed either by persons lacking necessary skills or in an environment lacking minimal medical standards or both; ${ }^{5}$ their worldwide incidence being 21.6 million in 2008 and almost all occurred in developing countries. ${ }^{3}$ In 2008 the total pregnancies worldwide were estimated to be 210 million; so it was estimated that 1 in 10 pregnancies ended in unsafe abortions ${ }^{6}$ which in turn were responsible for about 47000 maternal deaths in 2008 worldwide. ${ }^{3}$ Inspite of the liberal MTP Act in India since 1971, the ratio between safe and unsafe abortions is still 2:3. ${ }^{7}$ To decrease the incidence, Government of India in 2002 approved abortion pill (containing combination of mifepristone and misoprostol -both FDA approved schedule $\mathrm{H}$ drugs) for termination of early first trimester pregnancies. ${ }^{8}$ Various regimens are available; the most widely accepted one includes mifepristone $200 \mathrm{mg}$ orally followed by misoprostol $400 \mathrm{mcg}$ vaginally or orally 1 to 3 days later. Though introduction of medical abortion has decreased the complications related to surgical abortion, 
it needs emphasis that medical abortion if taken without supervision can itself be life threatening at times.

\section{METHODS}

This is a retrospective observational study, conducted at NDMC Medical College and Hindu Rao Hospital, New Delhi, India. Record of 200 patients who reported to Gynecology emergency with signs and symptoms suggestive of abortion process was evaluated. We selected patients with history of abortion pill intake and those who bought these pills without prescription were included in the study group. We tried to search for the record regarding who prescribed the pills, the method of intake of pills, any prior investigations done to confirm the pregnancy, the presenting complaints, final diagnosis and management.

\section{RESULTS}

It was striking to note the fact that $43 \%(86 / 200)$ patients gave history of intake of abortion pills. Among them only $18.60 \%(16 / 86)$ patients bought pills with prescription by qualified medical practitioners, rest $81.39 \%$ (70/86) bought them over the counter without prescription and these 70 patients were included in the study group. $54.28 \%(38 / 70)$ women had age $\leq 30$ years and $45.71 \%$ $(32 / 70)$ were $>30$ years of age. $18.57 \%(13 / 70)$ women were primigravida and the rest were multigravida. $15.71 \%$ (11/70) patients had previous delivery done by caesarian section. $42.85 \%(30 / 70)$ patients belonged to lower socioeconomic status, $48.57 \%(34 / 70)$ to middle socioeconomic status while $8.57 \%(6 / 70)$ belonged to upper socioeconomic status. The pills were bought by male counterpart in majority of the cases; the exact figures could not be calculated due to incomplete data. $42.85 \%(30 / 70)$ patients had history of having taken abortion pills for termination of previous pregnancies also. 90\% (63/70) patients were not using any kind of contraceptive method.

Since it was a retrospective study, the data regarding patient's knowledge about medical abortion was grossly incomplete. For that purpose we tried to contact those patients telephonically whose phone numbers were available in the records. However the exact figures couldn't be calculated. With whatever limited data that could be retrieved, it was found that $28.57 \%$ (20/70) patients, all using it for the first time had no knowledge about it at all. Among those who had some knowledge, the information was mostly received by relatives, friends and pharmacists and was largely incomplete. Very few patients had some information regarding gestational age up to which medical abortion is recommended, the normal amount and duration of bleeding associated with medical abortion, the side effects related to the regimen, when to report to hospital immediately and regarding whether or not a visit to a qualified medical professional is required prior to pill intake.

Only $55.71 \%$ (39/70) patients took the abortion pills as per the recommended standard protocol as far as the dose and regimen were concerned. To confirm pregnancy before abortion pill intake, urinary pregnancy test was done by $91.42 \%$ (64/70) patients whereas ultrasound was done by $15.71 \%(11 / 70)$ patients to confirm pregnancy and its location. Gestational age at time of pill intake was $\leq 8$ weeks, between $8-12$ weeks and $>12$ weeks in $45.71 \%$ $(32 / 70), 40 \%(28 / 70)$ and $14.28 \%(10 / 70)$ patients respectively. Time interval between pill intake and reporting to hospital was $\leq 2$ days, 3-7 days and $>7$ days in $25.71 \%(18 / 70), 31.42 \%(22 / 70)$ and $42.85 \%(30 / 70)$ patients respectively. $55.71 \%(39 / 70)$ patients had hemoglobin $>8 \mathrm{gms}, 37.14 \%(26 / 70)$ between $6-8 \mathrm{gms}$ and $7.14 \%(5 / 70)$ patients had hemoglobin $<6 \mathrm{gms}$.

Table1: Final diagnosis and management of patients (70) in different gestational age groups.

\begin{tabular}{|c|c|c|c|c|c|c|c|c|}
\hline $\begin{array}{l}\text { Gestational } \\
\text { age } \\
\text { (weeks) }\end{array}$ & $\begin{array}{l}\text { Number } \\
\text { of patients } \\
\text { (70) }\end{array}$ & $\begin{array}{l}\text { Complete } \\
\text { abortion } \\
\text { (15) }\end{array}$ & $\begin{array}{l}\text { Incomplete } \\
\text { abortion } \\
\text { (33) }\end{array}$ & $\begin{array}{l}\text { Missed } \\
\text { abortion } \\
(8)\end{array}$ & $\begin{array}{l}\text { Septic } \\
\text { abortion } \\
(5)\end{array}$ & $\begin{array}{l}\text { Ectopic } \\
\text { pregnancy } \\
\text { (4) }\end{array}$ & $\begin{array}{l}\text { Molar } \\
\text { pregnancy } \\
\text { (1) }\end{array}$ & $\begin{array}{l}\text { Threatened } \\
\text { abortion } \\
\text { (4) }\end{array}$ \\
\hline$\leq 8$ weeks & 32 & 14 & 13 & 1 & _ & 4 & _ & _- \\
\hline Management & & $\begin{array}{l}\text { No } \\
\text { intervention }\end{array}$ & $\begin{array}{l}\text { Medical -8 } \\
(\mathrm{S}-8) \\
\text { SE-5 }\end{array}$ & $\begin{array}{l}\text { Medical -1 } \\
(\mathrm{S}-1)\end{array}$ & - & $\begin{array}{l}\text { Immediate } \\
\text { laparotomy-2 } \\
\text { Medical -2 } \\
\text { (S-1; } \\
\text { F-1 followed by } \\
\text { laparotomy) }\end{array}$ & - & - \\
\hline $\begin{array}{l}\text { Between 8- } \\
12 \text { weeks }\end{array}$ & 28 & 1 & 15 & 5 & 5 & - & 1 & 1 \\
\hline Management & & $\begin{array}{l}\text { No } \\
\text { intervention }\end{array}$ & $\begin{array}{l}\text { Medical -2 } \\
(\mathrm{S}-2) \\
\text { SE-13 }\end{array}$ & $\begin{array}{l}\text { Medical -5 } \\
\text { (S-4; } \\
\text { F-1 followed } \\
\text { by SE) }\end{array}$ & $\begin{array}{l}\text { SE under } \\
\text { antibiotic } \\
\text { cover-5 }\end{array}$ & - & SE-1 & Absconded -1 \\
\hline$>12$ weeks & 10 & _- & 5 & 2 & - & - & - & 3 \\
\hline Management & & & SE-5 & $\begin{array}{l}\text { Medical -2 } \\
\text { (S-1; } \\
\text { F-1 followed } \\
\text { by SE) }\end{array}$ & - & - & - & $\begin{array}{l}\text { Medical -2 } \\
(\mathrm{S}-2) \\
\text { Absconded- } 1\end{array}$ \\
\hline
\end{tabular}

S-Successful; F-Failure; SE-suction evacuation; Medical-medical management 
Most common presenting complaint was related to varying amount of bleeding per vaginum met in $97.14 \%$ $(68 / 70)$ patients which included heavy bleeding $(25.71 \%$; $18 / 70)$, persistent bleeding $(57.14 \% ; 40 / 70)$, spotting $(7.14 \% ; 5 / 70)$ and persistent amenorrhea $(7.14 \% ; 5 / 70)$. The second most common complaint was abdominal pain met in $30 \%(21 / 70)$ patients. $8.57 \%(6 / 70)$ patients had severe abdominal pain out of which 2 had ruptured ectopic and 4 were in process of expulsion. Symptoms involving gastrointestinal tract (nausea, vomiting and diarrhea) were present in $14.28 \%$ (10/70) patients. $2.85 \%$ (2/70) patients gave history of syncopal attacks (both were diagnosed to have ruptured ectopic pregnancies). $7.14 \%(5 / 70)$ patients presented to emergency in shock out of which 2 had ruptured ectopic, 2 had severe anemia with incomplete abortion and 1 had severe anemia with molar pregnancy with profuse bleeding. $11.42 \%(8 / 70)$ patients gave history of chills after pill intake while $7.14 \%(5 / 70)$ patients gave history of persistent fever and these were worked on the lines of septic abortion.

Final diagnosis was complete abortion in $21.42 \%(15 / 70)$ patients, incomplete abortion in $47.14 \%$ (33/70), missed abortion in $11.42 \%(8 / 70)$, septic abortion in $7.14 \%$ $(5 / 70)$, threatened abortion in $5.71 \%$ (4/70), ectopic pregnancy in $5.71 \%(4 / 70)$ and molar pregnancy in $1.42 \%(1 / 70)$ patients and they were managed accordingly as per standard guidelines (Table 1).

Medical management in patients who opted for the same, was successful in all patients with incomplete abortion (using single dose of $400 \mathrm{mcg}$ misoprostol vaginally) and threatened abortion (using misoprostol $400 \mathrm{mcg}$ vaginally 4 hourly for maximum five doses); in 6 out of 8 patients with missed abortion (using single dose of $800 \mathrm{mcg}$ misoprostol vaginally) and in 1out of 2 patients with ectopic gestation (using single dose methotrexate regimen). Blood was transfused to all 5 patients who presented in shock. All the patients were counseled regarding contraception before discharge.

\section{DISCUSSION}

Certain facts were highlighted in our study and need discussion. First fact is that most of the couples are still not practicing any regular contraceptive method and hence the need for abortion arises. In our study this incidence was $90 \%$. It has been estimated that over $40 \%$ of pregnancies worldwide are unplanned - the result of non-use of contraception ${ }^{6}$. The United Nations Population Division (UNPD) estimates that in 2007, in developing regions some 110 million married/cohabiting women had an unmet need for family planning ${ }^{9}$ and three out of four unsafe abortions could be eliminated if the need for family planning were fully met ${ }^{10}$. Another point is that a large number of women now days are opting for abortion pills for termination of unwanted pregnancies. In our study $43 \%$ (86/200) patients gave history of abortion pill intake. Other important fact that needs to be addressed is that unsupervised medical abortions with associated apprehension and ignorance increase the number of unnecessary hospital visits; thereby increasing the hospital burden as well as the cost burden. Further, hospital admission affects women's choice regarding subsequent management thereby unnecessarily decreasing the success rate and acceptability of this wonder drug. In our study $21.42 \%$ (15/70) patients had already complete abortion on admission and their anxiety and unawareness about normal abortion process associated with pill was responsible for unjustified hospital visits. Also out of 33 patients with incomplete abortion, only 10 opted for conservative medical management whereas 23 preferred suction evacuation. Another point of utmost importance is that this unethical practice of over the counter sale of abortion pills can prove life threatening at times as is evident from our study where 4 patients had ectopic pregnancies, 5 had septic abortion and 5 had severe anemia.

The government of India should take concrete steps to improve the situation. First and most important step is to increase the awareness among masses of the fact that most of the abortions are legal under varying grounds as per MTP act and women should take advantage of their legal right to abortion. It's high time that they should break social taboos and come forward to get the benefit. People should be aware of various methods available for termination of pregnancy, their associated advantages and complications, the indications for termination of pregnancy as per MTP act and the places where Medical termination of pregnancy can be done. This can be achieved through public forums, posters and audiovisual aids. Another point that should be emphasized is that abortion pill should always be taken under supervision of a qualified doctor and over the counter sale should be prohibited. But one should also not forget the background to which these patients belong. $42.85 \%$ (30/70) patients in our study belonged to lower socioeconomic status and $48.57 \%(34 / 70)$ to middle socioeconomic status. Stringent measures taken to stop over the counter sale of abortion pill may force these women to adopt unsafe illegal surgical abortions again. So it's better to educate pharmacists who can pursue the patients to visit a doctor before taking pills and also they should be provided with handouts which can be given to the patients to improve their knowledge regarding medical abortion.

Last but not the least is the fact that prevention is always better than cure. Improving sex education, motivating the people to adopt various contraceptive methods, regular as well as emergency contraceptive methods, and making them easily available and accessible can reduce the rate of unwanted pregnancies and hence the need for abortion to a great extent though it cannot completely eliminate the need.

To conclude, it will be impossible to reach the fifth United Nations Millennium Development goal of $75 \%$ 
reduction of maternal mortality worldwide unless unsafe abortions are urgently focused upon. Medical abortion is a step taken by the government as a measure to decrease maternal morbidity and mortality associated with abortion. But visiting a qualified doctor before medical abortion is very important for confirmation of the gestational age, ruling out ectopic gestation or any contraindications (for example local sepsis, pre existing anemia), counseling of the patient (regarding medical abortion regimen, abortion process, importance of follow up visits and contraception), prevent untoward complications, decrease hospital burden and to increase its success rate and acceptability. Hence over the counter sale of abortion pills should be scrutinized otherwise this wonderful drug can prove disastrous at times.

Funding: No funding sources

Conflict of interest: None declared

Ethical approval: The study was approved by the Institutional Ethics Committee

\section{REFERENCES}

1. World Health Organization. The global burden of disease, 2004 update. Geneva, World Health Organization, 2008.

2. World Health Organization. The World Health Report 2005. Make Every Mother and Child Count. The World Health Organization: Geneva. WHO, 2005.

3. World Health Organization. Unsafe abortion: Global and regional estimates of the incidence of unsafe abortion and associated mortality in $2008.6^{\text {th }}$ edition.
Geneva, Switzerland: World Health Organization, 2011.

4. Grimes DA, Benson J, Singh S, Romero M, Ganatra B, Okonofua FE, et al. Unsafe abortion: the preventable pandemic. The Lancet Sexual and Reproductive Health Series. 2006;368(9550):190819.

5. Boland R, Katzive L. Developments in laws on induced abortion: 1998-2007. International Family Planning Perspectives. 2008;34(3):110-20.

6. Singh S, Wulf D, Hussain R, Bankole A. Sedgh G. Abortion worldwide: a decade of uneven progress. New York, Guttmacher Institute, 2009.

7. Unsafe abortions: eight maternal deaths every hour. Editorial. The Lancet. 2009;374(9698):1301.

8. Ministry of Health \& Family Welfare (India). Annual report 2006-2007. New Delhi, Ministry of Health \& Family Welfare, Government of India, 2008.

9. Singh S, Darroch J, Vlassoff. M. Adding it up. The costs and benefits of investing in family planning and maternal and newborn health. New York, Guttmacher Institute, 2009.

10. United Nations Population Division. Department of Economic and Social Affairs. World contraceptive use 2007 (wallchart). New York, United Nations, 2009.

Cite this article as: Sharma R, Gupta M, Sharma S. Over the counter sale of abortion pills - time to act now. Int J Reprod Contracept Obstet Gynecol 2015;4:1053-6. 